\title{
微分方程组 $\dot{x}=a+\sum_{i+j=2} a_{i j} x^{i} y^{j}$, \\ $\dot{y}=b+\sum_{i+j=2} b_{i j} x^{i} y^{j}$ 至多存在两个极限环 \\ 索 光 佮 \\ （吉林省白城师范学院）
}

\section{一、问题与结果}

实系数二次微分方程组

$$
\begin{aligned}
& \dot{x}=a+a_{20} x^{2}+a_{11} x y+a_{02} y^{2}=P(x, y), \\
& \dot{y}=b+b_{20} x^{2}+b_{11} x y+b_{02} y^{2}=Q(x, y)
\end{aligned}
$$

的极限环个数问题, 董金柱教授作出实例指出一类二次对称向量场 (1) 式至少存在两个极限 环视。本文证明

定理 (1) 式至多存在两个极限环.

\section{二、定理的证明}

无忤于一般性, 可设 $a_{02}=0$, 即 (1) 式具有形状:

$$
\dot{x}=a+a_{20} x^{2}+a_{11} x y, \quad \dot{y}=b+b_{20} x^{2}+b_{11} x y+b_{02} y^{2} .
$$

事实上, 若 $a_{a 2} \neq 0$, 当 $b_{20}=0$ 时, 则把 $x$ 和 $y$ 的位置互换, (1) 式即具有 (2) 式形; 当 $b_{20} \neq 0$ 时, 则三次方程: $b_{20} K^{3}+\left(b_{11}-a_{20}\right) K^{2}+\left(b_{02}-a_{11}\right) K+a_{02}=0$ 至少有一个非零实根 2. 对 (1) 式作变换: $x=\bar{x}+\lambda \bar{y}, y=\bar{y}$, 则 (1) 式就变为 (2) 式形. 因此我们只就 (2) 式 来讨论就可以了.

由于 $a^{2}+b^{2}=0$ 时, (2) 式是齐次微分方程组, 因而无极限环. 所以我们总假定 $a^{2}+$ $b^{2} \neq 0$. 这时原点不是奇点. 注意到

$$
P(-x,-y)=P(x, y), \quad Q(-x,-y)=Q(x, y),
$$

知 (2) 式的奇点数和极限环数都是非负偶数. 以下分两种情形来证明定理.

i) $a=0$. 这时 (2) 式无极限环.

事实上, 当 $a=0$ 时, 由于 $b \neq 0$, 所以 (2) 式至少有一条直线解 $x=0$. 但具有一条直线 解的二次微分方程组极限环数不超过 $1^{[2]}$. 又 (2) 式的极限环数是非负偶数, 不超过 1 的非负 偶数只能是零. 所以 $a=0$ 时, (2) 式无极限环.

ii） $a \neq 0$, 这种情形下, 我们先对 (2) 式进一步简化:

若 (2) 式无奇点, 则无极限环, 因此不妨设有一奇点 $\left(x_{1}, y_{1}\right)$, 由条件 (3) 知 $\left(-x_{1},-y_{1}\right)$ 也是奇点. 下面证明, 总存在非奇异仿射变换, 把以上两个奇点变为 $( \pm 1,0)$, 且不改变 $(2)$

本文 1981 年 5 月 4日收到. 
式的形式. 事实上, 因 $a \neq 0$, 所以 $x_{1} \neq 0$. 当 $y_{1}=0$ 时, 这样的变换可取 $x=x_{1}, \underline{x}, y=\bar{y}$; 当 $y_{1} \neq 0$ 时,这样的变换可取 $x=x_{1} \bar{x}, y=y_{1} \bar{x}+\bar{y}$. 变换后, 仍记 $\bar{x}, \bar{y}$ 为 $x, y$, 则(2) 式变 为:

$$
x=a-a x^{2}+a_{11}^{\prime} x y, \quad y=b-b x^{2}+b_{11}^{\prime} x y+b_{02}^{\prime} y^{2},
$$

在 (4) 式中引人时间变换 $\tau=a t$, 变换后若仍记 $\tau$ 为 $t$, 且记:

$\alpha=\frac{a_{11}^{\prime}}{a}, l=\frac{b}{a}, m=\frac{b_{11}^{\prime}}{a}, n=\frac{b_{02}^{\prime}}{a}$, 则 (4) 式变为:

$$
t=1-x^{2}+\alpha x y, \quad \dot{y}=l-l x^{2}+m x y+n y^{2} .
$$

当 $a=0$ 时, (5) 式变为:

$$
\dot{x}=1-x^{2}, \quad \dot{y}=l-l x^{2}+m x y+n y^{2} .
$$

当 $\alpha \neq 0$ 时, 用 $y=\frac{1}{\alpha} \bar{y}$ 变换(5) 式后,仍记 $\bar{y}$ 为 $y$, 且仍用 $l, n$ 去记 $\alpha$ 及 $\frac{n}{\alpha}$, (5)式变为:

$$
t=1-x^{2}+x y, \quad y=l-l x^{2}+m x y+n y^{2} .
$$

下面只要对 (6) 式和 (7) 式证明定理就可以了.

对于 (6) 式,它有两条直线解 $x= \pm 1$, 无环 ${ }^{[2]}$.

对于 (7) 式, $x=0$ 时, $\dot{x}=1$. 因此 $x=0$ 是无切直线, 所以(7)式的极限环不与 $x=0$ 相交. 若能证得当 $x>0$ 时, (7) 式至多一个极限环, 则再利用条件 (3) 知 (7)式的极限环数 不超过 2. 现证 (7) 式在 $x>0$ 时至多一个极限环.

在 (7) 式中作变换: $\xi=1-x^{2}+x y, x=x, d t=x d \tau$, 则 (7)式变为:

$\frac{d x}{d \tau}=x \xi$,

$\frac{d \xi}{d \tau}=(m+2 n-1) x^{2} \xi-(2 n+1) \xi+(n+1) \xi^{2}-(l-m-n) x^{4}+(l-m-2 n) x^{2}+n$.

在 (8) 式中,再引人变换: $u=x^{2}, \xi=\xi$ 变为:

$\frac{d u}{d \tau}=2 u \xi$,

$\frac{d \xi}{d \tau}=(m+2 n-1) u \xi-(2 n+1) \xi+(n+1) \xi^{2}-(l-m-n) u^{2}+(l-m-2 u) u+n$.

由于 (7) 式在 $x>0$ 半平面上的极限环数和(9)式在 $u>0$ 半平面上的极限环数相等,而 （9）式则是具有直线解的二次微分方程组，它在 $(u, \xi)$ 全平面上至多一个极限环，因此在 $u>0$ 上 (9) 式的极限环数不超过 1 , 从而 (7) 式在 $x>0$ 上极限环数不超过 1 . 至此定理完全证 毕.

致谢：本文在导师秦元助教授指导下完成，作者深表谢意.

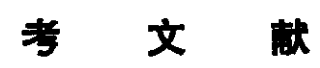

[1] 䅈元勋, 微分方程所定义的积分曲线(下), 科学出版社, 1959，391-396.

[2] 叶彦详,新疆大学学报, $1980,1: 10$. 